\title{
Interdisciplinaridade no Ensino de Física e Computação na Educação Básica: Relato de Experiência de um curso de Formação Inicial e Continuada sob a Perspectiva na Construção de Experimentos
}

\author{
Veruska Machado \\ IFB/Instituto Federal de Brasília \\ Brasília DF Brasil \\ veruska.machado@ifb.edu.br
}

\author{
Thiago Amorim \\ IFB/Instituto Federal de Brasília \\ Brasília DF Brasil \\ thiago.amorim@ifb.edu.br
}

\author{
Petrus Barros \\ IFB/Instituto Federal de Brasília \\ Brasília DF Brasil \\ petrus.barros@ifb.edu.br
}

\begin{abstract}
RESUMO
A formação do estudante do século XXI passa pela perspectiva de formação tecnológica, pela necessidade de letramentos digitais que o permita atuar como produtor crítico na sociedade moderna. A Sociedade Brasileira de Computação (SBC) em seu documento Itinerário Formativo de Computação, apresenta a necessidade da formação em computação na educação básica, que hoje é comparável à alfabetização no passado, contribuindo para a compreensão plena do mundo imerso em tecnologias digitais. Frente a esta realidade, o presente projeto voltou-se ao ensino de ciências naturais e levanta-se a questão: como desenvolver estas habilidades nas aulas de ciências na educação básica? Este trabalho teve como objetivo o ensino de física e computação de forma interdisciplinar na perspectiva do letramento científico e digital, por meio de desenvolvimento de projetos. Os projetos que foram desenvolvidos pelos estudantes durante as aulas consistiam na criação de experimentos físicos através da plataforma Arduino e seus respectivos sensores, utilizando conceitos de computação, programação e robótica. Para isso formou-se uma equipe multidisciplinar composta por professores da área da física e computação para planejamento coletivo a cada encontro do curso, desenvolvendo de forma interdisciplinar os conteúdos a serem abordados de forma a fornecerem subsídios ao estudante para desenvolver o experimento. Os resultados da aplicação deste projeto apontam que a construção dos experimentos realizada pelos estudantes foi um facilitador de aprendizagem de conteúdos de física e computação. Por fim percebeu-se também um crescente engajamento dos estudantes ao longo das aulas ao colocá-los no papel ativo da aprendizagem como produtores de artefatos tecnológicos.
\end{abstract}

Fica permitido ao(s) autor(es) ou a terceiros a reprodução ou distribuição, em parte ou no todo, do material extraído dessa obra, de forma verbatim, adaptada ou remixada, bem como a criação ou produção a partir do conteúdo dessa obra, para fins não comerciais, desde que sejam atribuídos os devidos créditos à criação original, sob os termos da licença CC BY-NC 4.0. EduComp'21, Abril 27-30, 2021, Jataí, Goiás, Brasil (On-line)

(C)2021 Copyright mantido pelo(s) autor(es). Direitos de publicação licenciados à Sociedade Brasileira de Computação (SBC).

\section{PALAVRAS-CHAVE}

Ensino, Física, Computação, Robótica, Experimento, Arduino.

\section{Introdução}

Vivemos em uma realidade imersa em inovações tecnológicas constantes que emergem e tornam-se indispensáveis em todas as áreas. A todo momento há evoluções e revoluções tecnológicas que afetam todas as áreas da sociedade, desde o entretenimento e a cultura até o trabalho. Os processos de aprendizagem também são afetados por essa relação indissociável entre sociedade e tecnologia. A formação do estudante, neste contexto, não pode ser indiferente a esta realidade, pois há a necessidade de uma formação tecnológica que o permita atuar como produtor crítico na sociedade moderna. Não basta ter habilidade com as ferramentas TICs disponíveis para acesso à informação, exige-se deste indivíduo pensamento crítico, argumentação e capacidade de resolução de problemas.

Nesse sentido, a Sociedade Brasileira de Computação (SBC, 2019), ao defender a formação em computação na educação básica, compara esta necessidade à alfabetização no passado, considerando que os conceitos fundamentais de computação permitem que os estudantes compreendam e atuem de forma mais completa no mundo que os cerca.

Em paralelo, a Base Nacional Comum Curricular (Brasil, 2018), tem como um de seus objetivos levar aos estudantes o contato com processos, práticas e procedimentos da investigação científica para que eles sejam capazes de intervir na sociedade. Neste percurso, as vivências e os interesses dos estudantes sobre o mundo natural e tecnológico devem ser valorizados. Essa prática ainda é difícil de ser desenvolvida, pois muitas áreas, incluindo a física, ainda se organizam de modo a privilegiar o estudo de conceitos, linguagem e metodologias de cada campo do conhecimento, tornando as aprendizagens pouco eficientes para interpretação e intervenção na realidade prática.

Sendo este nosso cenário atual, não há dúvidas de que se trata de um momento oportuno para abordar novos métodos e processos para o ensino, em especial, métodos que permitam mais autonomia no processo de aprendizagem. Diante disso, levantou-se o seguinte questionamento: como desenvolver essas habilidades nas aulas de ciências, 
especificamente na área da física, na educação básica, em meio à necessidade inerente da formação tecnológica e em computação, de forma a facilitar a aprendizagem de ambas as áreas?

Assim, o objetivo geral deste projeto foi planejar, desenvolver e aplicar um curso de curta duração na modalidade de formação inicial e continuada (FIC) para desenvolver os letramentos científico e digital em estudantes do ensino médio, através do ensino de física e computação, utilizando-se, para isso, uma metodologia centrada no desenvolvimento de projetos interdisciplinares por meio da criação de experimentos físicos pelos próprios estudantes, utilizando conceitos de computação implementados na plataforma Arduino, seus sensores e atuadores. Para isto foi necessário montar uma equipe multidisciplinar, composta por professores orientadores e estudantes licenciandos na área da física e computação, para o desenvolvimento e avaliação constante das aulas e aplicação no curso de Formação Inicial e Continuada (FIC).

O curso FIC, intitulado "Robótica e Física para estudantes do ensino médio", teve duração de 40h/a e ocorreu no Instituto Federal de Brasília (IFB), campus Taguatinga, Distrito Federal. Teve como público-alvo estudantes que cursavam o ensino médio nas redes pública e privada, da $1^{\text {a }}$ à $3^{\text {a }}$ série do ensino médio, com idades entre 15 e 18 anos, e o curso ocorreu aos sábados das $08 \mathrm{~h}$ às $11 \mathrm{~h} 40$.

Como proposta metodológica, utilizou-se a aprendizagem baseada em projetos: a cada aula realizava-se um pequeno projeto/experimento e, ao final do curso, como projeto final, foi construída uma miniestação meteorológica aplicando os conceitos de física para análise da estação e os de computação para a sua construção. Além disso, o curso foi planejado em duas frentes, uma voltada para a ação em sala de aula com os estudantes do ensino médio e outra voltada para o planejamento contínuo do curso pelos professores, juntamente com os licenciandos das áreas de física e computação.

A primeira frente focou-se na integração em sala de aula entre teoria e prática dos conteúdos de física e computação, por meio da criação do experimento pelos próprios estudantes utilizando Arduino, seus sensores e atuadores.

A segunda frente focou-se no acompanhamento e desenvolvimento constante do curso devido à necessidade interdisciplinar proposta. Após cada encontro, realizava-se uma reunião com os professores orientadores e licenciandos para análise da última aula e planejamento das ações da próxima. Para auxiliar a análise, um questionário era aplicado aos estudantes no final de cada aula para feedback. As respostas eram analisadas e levadas em conta para o planejamento do encontro seguinte.

O curso FIC foi desenvolvido com a expectativa de que os estudantes alcançassem os seguintes objetivos: i) compreender, por meio de aplicações práticas, os conteúdos presentes nos objetivos de aprendizagem das aulas relacionadas à área de física e computação; ii) estimular criatividade, autonomia, curiosidade e resolução de problemas, proporcionando uma maior apropriação e internalização dos conhecimentos/conceitos físicos e computacionais abordados, de forma que tais conceitos (teoria) guiem a criação e implementação de tecnologias para experimentos e/ou soluções de problemas do cotidiano (prática); iii) a partir da observação dos resultados da aplicação do experimento, retornar à teoria para alimentar uma nova prática (práxis), fomentando assim a experimentação, a observação, a criação de teses, a obtenção dos resultados e a dedução para desenvolvimento do letramento científico e digital.

Para avaliação do estudante no curso, foram consideradas observações realizadas pelos docentes regentes, participação, execução e construção dos projetos durante as aulas pelos estudantes e construção do projeto final. Ao final do curso, os estudantes responderam a um questionário anônimo realizado no último encontro com a finalidade de o estudante avaliar o curso como um todo, bem como o seu próprio desenvolvimento.

Diante desta perspectiva, este trabalho relata a experiência de aplicação do curso "Robótica e Física para estudantes do ensino médio" conduzido por professores orientadores do IFB e aplicado por licenciandos da área de física e computação da mesma instituição.

\section{O Ensino de Física e Computação na Perspectiva do Letramento Científico e Digital}

Para justificar o curso, recorreu-se ao que a Base Nacional Comum Curricular (BNCC) do ensino médio apresenta, em sua competência $n^{\circ} \mathbf{0} 3$, referente às ciências da natureza, destacando o necessário diálogo entre essa área e suas tecnologias:

Investigar situações-problema e avaliar aplicações do conhecimento científico e tecnológico e suas implicações no mundo, utilizando procedimentos e linguagens próprios das Ciências da Natureza, para propor soluções que considerem demandas locais, regionais e/ou globais, e comunicar suas descobertas e conclusões a públicos variados, em diversos contextos e por meio de diferentes mídias e tecnologias digitais de informação e comunicação (TDIC). (BNCC, 2018, p. 553)

Desta forma a competência no 3 da BNCC, referente às ciências da natureza, vão ao encontro ao ensino de fundamentos da área de computação. Segundo a SBC, a computação investiga processos de informação por meio do desenvolvimento de linguagens, de técnicas para descrever processos e de métodos de análise e resolução de problemas, tendo sua aplicação através do desenvolvimento de máquinas (computadores) capazes de armazenar estas informações, processá-las e distribuí-las de forma automatizada.

Em seu documento intitulado Diretrizes para ensino de Computação na Educação Básica, a SBC (2019) divide o ensino da área de computação em três eixos: Mundo Digital, Cultura Digital e Pensamento Computacional. O Mundo Digital é um ecossistema composto por máquinas físicas (elementos físicos, hardware) e também virtuais (programas e dados, softwares) criado para armazenar, processar e distribuir a informação, permitindo o acesso ao virtual. A Cultura Digital é o letramento em tecnologias digitais para se conseguir atuar, expressar, criar e se comunicar dentro do Mundo Digital de forma crítica e autônoma. O Pensamento Computacional consiste na capacidade de compreender, definir, modelar, comparar, solucionar, automatizar e analisar problemas e soluções de forma metódica e sistemática, para construção de algoritmos (sequência de atividades que leva a solução de um determinado problema) a serem implementados no Mundo Digital segundo suas definições. 
Para Bordini et al (2016), o pensamento computacional é um processo de resolução de problemas, que envolve as seguintes habilidades: formulação de problemas de uma forma que seja possível usar um computador e outras ferramentas para ajudar a resolvê-los; organização lógica e análise de dados; representação de dados através de abstrações, como modelos e simulações; soluções de automação através do pensamento algorítmico (como uma série de passos ordenados); identificação, análise e implementação de soluções possíveis com o objetivo de alcançar a combinação mais eficiente e eficaz das medidas e recursos; generalização e transferência desse processo de resolução para problemas variados.

Segundo a SBC (2019), para comunicação, expressão e utilização do Mundo Digital, é necessário um letramento em tecnologias digitais, um letramento digital. O Centro de Inovação para a Educação Brasileira (CIEB, 2020) destaca o letramento digital como:

os modos de ler e escrever informações, códigos e sinais verbais e não verbais com uso do computador e demais dispositivos digitais, abordando o desenvolvimento de habilidades relacionadas ao uso dos equipamentos e seus softwares com proficiência (CIEB, 2020, p. 18).

Assim, ao se buscar uma formação digital na perspectiva de autonomia do estudante, que vai além do papel de utilizador das tecnologias, mas também produtor crítico na resolução de problemas, se faz necessário um letramento digital na perspectiva do ensino de computação nas áreas de Pensamento Computacional, Mundo Digital e Cultura Digital.

Ao retornarmos à competência no 3 da BNCC, referente às ciências da natureza, podemos observar a relação entre o ensino do Mundo Digital e Cultura Digital no que diz respeito à utilização das tecnologias para "... comunicar descobertas e conclusões a públicos variados, em diversos contextos e por meio de diferentes mídias e tecnologias digitais de informação e comunicação (TDIC). (BNCC Ensino Médio, p. 115)". Quanto ao ensino do Pensamento Computacional e Mundo Digital, a relação ocorre na implementação de algoritmos construídos ao analisar “... situações-problema e avaliar aplicações do conhecimento científico e tecnológico e suas implicações no mundo, utilizando procedimentos e linguagens próprios das Ciências da Natureza, para propor soluções que considerem demandas locais, regionais e/ou globais... (BNCC Ensino Médio, p. 115) ".

Sobre a interdisciplinaridade entre ciências da natureza e computação, vale destacar ainda a possibilidade de o desenvolvimento de fundamentos do Mundo Digital, Cultura Digital e Pensamento Computacional auxiliar os estudantes a desenvolver-se melhor nos componentes curriculares da educação básica e, consequentemente, na sociedade moderna imersa em tecnologias. Ressalta-se que estes princípios são importantes para o desenvolvimento de algumas estratégias pedagógicas que permitem produtivo diálogo entre ciências da natureza e tecnologias, tais como a robótica e a modelagem 3D.

A abordagem de experimentação do curso parte do princípio de que a experimentação é um facilitador de aprendizagem. Santos (2005) enfatiza que:

O ensino por meio da experimentação é quase uma necessidade no âmbito das ciências naturais. Ocorre que podemos perder o sentido da construção científica se não relacionarmos experimentação, construção de teorias e realidade socioeconômica e se não valorizarmos a relação entre teoria e experimentação, pois ela é o próprio cerne do processo científico. (SANTOS, 2005, p. 61).

Já Bruner (1969) afirma que o processo de aprender está relacionado à descoberta, através da exploração de alternativas e do currículo em espiral. A exploração de alternativas se dá na investigação de problemas. As atividades propostas eram pautadas em situações problema, nas quais o estudante é instigado a uma solução. Ainda conforme Bruner, as investigações das atividades propostas devem ser "dirigidas" pelo professor de modo a não causar confusão no estudante, conforme Moreira (1999).

Bruner coloca a dúvida como a ativação do processo. É ela que instiga o estudante a buscar a aprendizagem. Esta dúvida é gerada no estudante a partir de uma situação problema. A experimentação é uma forma de envolver o estudante no processo de ensino e aprendizagem. Nos resultados, que serão apresentados no próximo tópico, ficará evidente o envolvimento dos estudantes nas atividades propostas do curso de forma positiva.

Cabe ressaltar ainda que o envolvimento dos estudantes foi fomentado pela adoção de um ensino pautado em projetos com o desenvolvimento de metodologias ativas. A aprendizagem baseada em projetos envolve o estudante como partícipe do processo pedagógico e se baseia em três princípios: i) a aprendizagem é contextual; ii) os estudantes são envolvidos em todo o processo ativamente; iii) o objetivo é alcançado por meio de interações sociais e do compartilhamento de conhecimentos (Vincent-Lancrin, 2020)

Por estes motivos, o objetivo geral do curso foi desenvolver os letramentos científico e digital em estudantes de ensino médio, utilizando, para isso, uma metodologia centrada no desenvolvimento de projetos interdisciplinares, tendo como enfoque as áreas da ciência de física e computação e como metodologia principal a aprendizagem baseada em projetos por meio da experimentação. Seus objetivos específicos foram: desenvolver oficinas para o ensino de princípios computacionais aliados ao Arduino; desenvolver e aplicar oficinas para aplicação de experimentos em física; desenvolver e aplicar oficinas com a utilização de tecnologias educacionais, como microcontrolador Arduino e programação, para experimentações em física, e desenvolver projetos pedagógicos que promovam a cultura maker.

O curso teve como base o ensino de física e computação de forma interdisciplinar e retroalimentável, através do desenvolvimento e da aplicação de experimentos físicos utilizando o microcontrolador Arduino como plataforma de implementação. A perspectiva era não limitar o estudante à função de executor e observador do experimento físico, mas que assumisse também o papel de criador e desenvolvedor do próprio experimento de forma a estimular sua criatividade, autonomia, curiosidade e resolução de problemas.

Para isso, fez-se necessário o domínio de conhecimentos de física e computação para implementação de experimentos em que os conceitos teóricos guiassem a criação de tecnologias para experimentos e/ou soluções de problemas no cotidiano prático.

Para o acompanhamento e constante planejamento do curso, determinou-se que, ao final de cada aula, os estudantes do curso responderiam a um formulário eletrônico de forma anônima sobre a experiência com a dinâmica, atividades 
desenvolvidas durante a aula, pontos positivos, pontos negativos e sugestões para melhoria. 0 anonimato permitiu que os estudantes respondessem livremente as perguntas e o formulário foi elaborado para ser o mais simples e objetivo possível para facilitar e incentivar a resposta. No formulário foi dividido o conteúdo da aula, apesar de ser interdisciplinar como um todo, em partes identificáveis pelos estudantes classificando-os em ótimo, bom, regular, ruim. Desta forma é possível estabelecer a qual momento da aula o estudante se referia, sendo possível uma intervenção na lacuna de aprendizado de cada aula. 0 estudante pode atribuir uma nota de 0 (zero) até $10(\mathrm{dez})$ da aula como um todo, esta informação nos permitiu estabelecer um parâmetro objetivo de avaliação contínua das aulas, avaliando de forma mais aprofundada caso a nota diminuísse de uma aula para a outra. Por fim havia duas questões subjetivas que os estudantes responderam com pontos positivos e pontos negativos sobre a aula. Isto nos permitiu continuar ações e estratégias de ensino que tiveram impacto positivo na aprendizagem e a rever ações que não facilitaram a aprendizagem dos estudantes. A Figura 1 ilustra um exemplo de questionário aplicado.

Como metodologia de acompanhamento e (re)planejamento do curso FIC, realizaram-se reuniões semanais entre licenciandos e orientadores para: análises da aula anterior; análises das respostas dos estudantes; apontamentos de melhorias com base nos feedbacks dos estudantes, licenciandos e orientadores; (re)planejamento coletivo das aulas e plano de ensino; e definição do grupo de licenciandos da aula seguinte. A metodologia de encontros semanais para (re)planejamento das aulas, com base nas informações das observações dos professores orientadores, dos licenciandos e também nas respostas dos questionários, favoreceu a reflexão acerca das práticas adotadas e a melhoria das aulas, principalmente em relação à abordagem de cada conteúdo e à escolha do experimento a ser desenvolvido na próxima aula.

\subsection{Aulas Curso FIC}

A metodologia definida para as aulas consistia na abordagem intercalada dos conteúdos de física e computação seguidos pela exemplificação prática destes com o uso de experimentos multidisciplinares implementados através do microcontrolador Arduino. Durante os dois primeiros horários de aula se desenvolviam pequenos projetos que resultavam na construção do produto final da aula nos dois últimos horários. Em um primeiro momento, os estudantes tinham contato com os conteúdos teóricos de física, depois o conteúdo de computação era abordado sob a perspectiva do projeto/experimento da aula. Neste momento era resgatada a teoria física trabalhada anteriormente, por fim era construído o projeto/experimento para verificação do conteúdo da física abordado inicialmente, utilizando-se da capacidade de automação do Arduino. Neste momento os estudantes tiveram contato com a teoria, construíram o aparato tecnológico utilizando conceitos de computação e tecnologias disponíveis para verificação da teoria na perspectiva da cultura maker (faça você mesmo), realizaram o experimento e analisaram os dados coletados comparando com a teoria e conceitos abordados em sala de aula, na perspectiva da práxis.

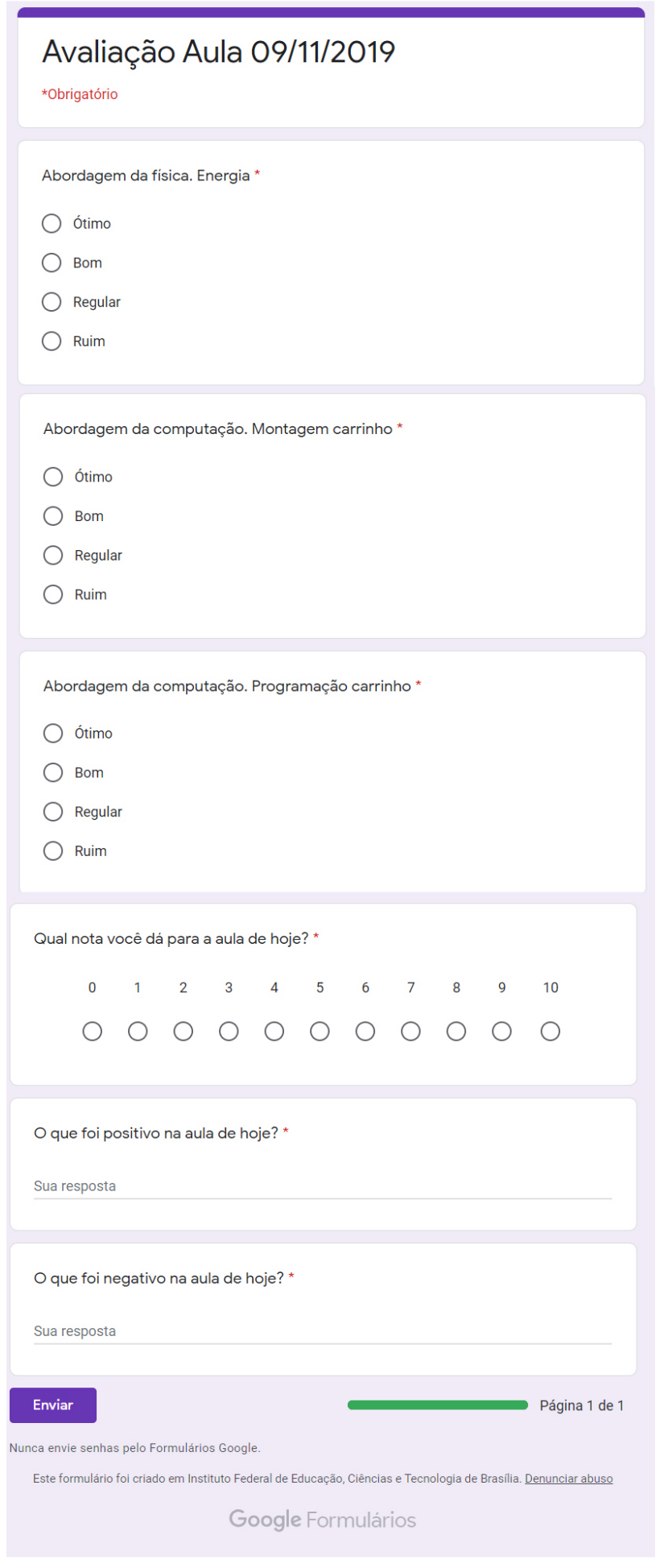

Figura 1 - Questionário Avaliação da Aula

Os estudantes eram avaliados durante a execução das atividades e pelos resultados obtidos na construção dos produtos finais de cada aula. Além disso, como avaliação final do curso, foi proposta a elaboração de um projeto final abarcando o conteúdo de física e computação ao longo do curso, concretizando-se na criação de uma miniestação meteorológica e sua posterior apresentação pelos estudantes na perspectiva dos conteúdos de física e computação. 
A seguir o Quadro 1 detalha as temáticas dos encontros, com duração de $4 \mathrm{~h}$ /a cada, sua metodologia, recursos e produtos criados.

\begin{tabular}{|c|c|c|}
\hline Encontro & Temática & Produto/Experimento \\
\hline $1^{\mathrm{o}}$ & $\begin{array}{l}\text { Circuitos } \\
\text { eletrônicos, lei } \\
\text { de Ohm, } \\
\text { corrente } \\
\text { elétrica, } \\
\text { potencial } \\
\text { elétrico, } \\
\text { Arduino. }\end{array}$ & $\begin{array}{l}\text { Construção de semáforo } \\
\text { com LED’s e resistores em } \\
\text { série. }\end{array}$ \\
\hline $2^{o}$ & $\begin{array}{l}\text { LED no padrão } \\
\text { RGB, associação } \\
\text { de resistores, } \\
\text { código de cores } \\
\text { de resistores. }\end{array}$ & $\begin{array}{l}\text { Circuito utilizando LED } \\
\text { RGB com associação de } \\
\text { resistores em série. }\end{array}$ \\
\hline $3^{\circ}$ & $\begin{array}{l}\text { Termologia: } \\
\text { capacidade } \\
\text { térmica, } \\
\text { calorimetria, lei } \\
\text { do resfriamento } \\
\text { de Newton. } \\
\text { Estruturas de } \\
\text { decisão, } \\
\text { operadores } \\
\text { matemáticos e } \\
\text { sensor de } \\
\text { temperatura. }\end{array}$ & $\begin{array}{l}\text { Experimento com sensor } \\
\text { de temperatura, } \\
\text { construção de tabela e a } \\
\text { construção do gráfico da } \\
\text { lei de resfriamento } \\
\text { utilizando o programa } \\
\text { QtiPlot. }\end{array}$ \\
\hline $4^{\mathrm{o}}$ & $\begin{array}{l}\text { Simulador } \\
\text { online de } \\
\text { circuitos e } \\
\text { Arduino } \\
\text { (Tinkercad) }\end{array}$ & $\begin{array}{l}\text { Criação de circuitos } \\
\text { propostos para revisão } \\
\text { dos encontros anteriores. }\end{array}$ \\
\hline $5^{\mathrm{o}}$ & $\begin{array}{l}\text { Velocidade } \\
\text { média e } \\
\text { aceleração } \\
\text { média. } \\
\text { Operadores } \\
\text { lógicos, } \\
\text { estruturas de } \\
\text { decisão e } \\
\text { sensores } \\
\text { infravermelhos. }\end{array}$ & $\begin{array}{l}\text { Experimento de } \\
\text { velocidade média e } \\
\text { aceleração média. }\end{array}$ \\
\hline $6^{0}$ & $\begin{array}{l}\text { Força } \\
\text { Magnética (Lei } \\
\text { de Lorentz), } \\
\text { Motores } \\
\text { elétricos e Lei } \\
\text { de Faraday- }\end{array}$ & $\begin{array}{l}\text { Protótipo conceitual de } \\
\text { motor elétrico. }\end{array}$ \\
\hline
\end{tabular}

\begin{tabular}{|c|c|c|}
\hline & $\begin{array}{l}\text { Lenz e a } \\
\text { implicação do } \\
\text { uso do Arduino } \\
\text { como fonte de } \\
\text { tensão elétrica. }\end{array}$ & \\
\hline 70 & $\begin{array}{l}\text { Força, Leis de } \\
\text { Newton, ponte } \\
\text { H e estruturas } \\
\text { de repetição na } \\
\text { programação e } \\
\text { controle de } \\
\text { motores via } \\
\text { software e } \\
\text { debug. }\end{array}$ & $\begin{array}{l}\text { Protótipo de carrinho } \\
\text { controlado via } \\
\text { programação. }\end{array}$ \\
\hline $8^{\circ}$ & $\begin{array}{l}\text { Umidade } \\
\text { relativa do ar, } \\
\text { amplitude } \\
\text { térmica, sensor } \\
\text { de umidade e o } \\
\text { display LCD. }\end{array}$ & $\begin{array}{l}\text { Experimento de } \\
\text { mensuração temperatura } \\
\text { e umidade do ar. }\end{array}$ \\
\hline 9o & $\begin{array}{l}\text { Pressão } \\
\text { atmosférica e } \\
\text { nível de } \\
\text { precipitação. } \\
\text { Sensor de } \\
\text { chuva, pressão } \\
\text { atmosférica e } \\
\text { gás } \mathrm{CO}_{2} .\end{array}$ & $\begin{array}{l}\text { Experimento de detecção } \\
\text { pressão atmosférica e } \mathrm{CO}_{2} \\
\text { utilizando o sensor de } \\
\text { gases }\end{array}$ \\
\hline $10^{\circ}$ & $\begin{array}{l}\text { Construção e } \\
\text { apresentação } \\
\text { do projeto final: } \\
\text { apresentação } \\
\text { dos projetos de } \\
\text { cada grupo. }\end{array}$ & $\begin{array}{l}\text { Construção e } \\
\text { apresentação da estação } \\
\text { meteorológica }\end{array}$ \\
\hline
\end{tabular}

Quadro 1: Temática, produto/experimento das aulas do curso

A Figura 2 exemplifica os produtos e experimentos elaborados ao longo das aulas do curso relatadas no Quadro 1.

Os materiais e recursos utilizados durante o curso foram: quadro, pincel, apagador, projetor de imagens, laboratório de informática com acesso à Internet, microcontrolador Arduino UNO e componentes eletrônicos necessários para criação de produto. Já os recursos de software utilizados foram: IDE Arduino e simulador online de circuitos Tinkercad e o QtiPlot. Todos os softwares utilizados estão disponíveis gratuitamente na internet e os recursos eletrônicos foram adquiridos pela instituição em projeto contemplado em edital que previa a compra deste material. 

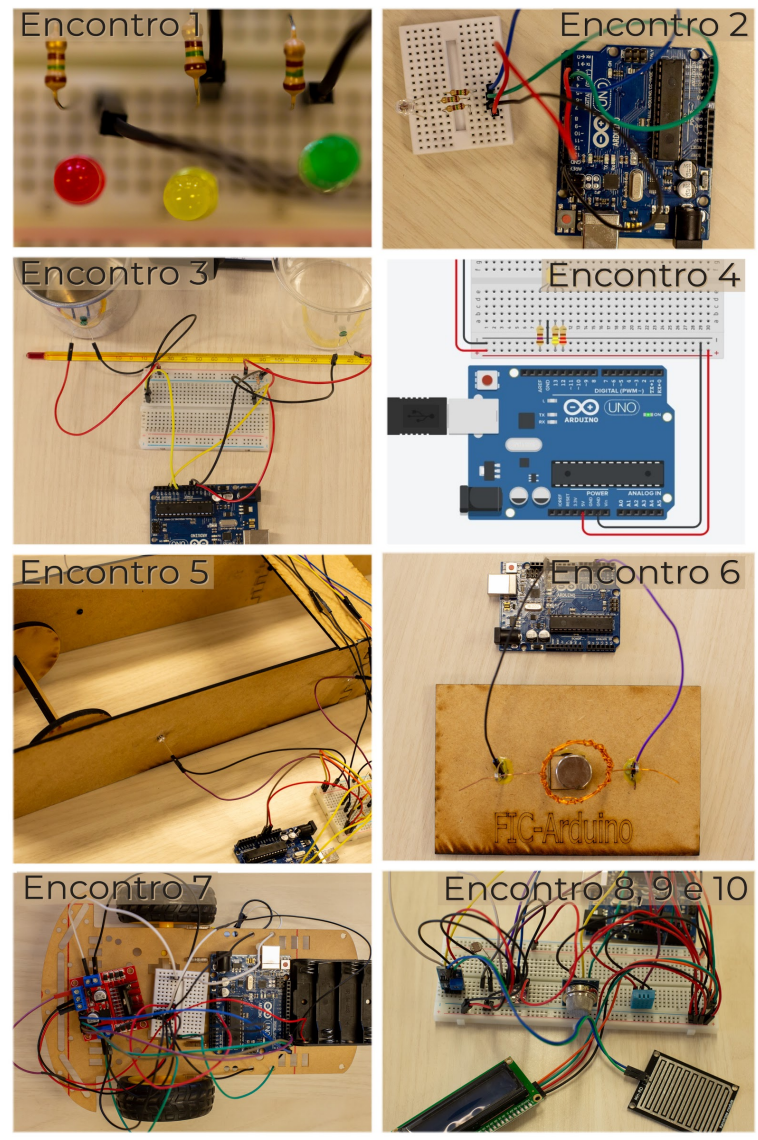

Figura 2 - Produtos educacionais construídos durante a realização do curso

O Quadro 2 mostra o plano de ensino utilizado ao longo do curso e o conteúdo programático abordado em cada encontro.

\begin{tabular}{|c|c|}
\hline Encontro & Conteúdo Programático \\
\hline $1 \stackrel{0}{0}$ & $\begin{array}{l}\text { - Avaliação Diagnóstica } \\
\text { - Circuito Gerador - Resistor } \\
\text { - Leis de Ohm. } \\
\text { - Corrente elétrica } \\
\text { - Microcontrolador (Arduino Uno) } \\
\text { - Meio analógico e meio digital } \\
\text { - Portas Digitais e Analógicas } \\
\text { - Sensores e Atuadores } \\
\text { - Protoboard. } \\
\text { - IDE Arduino } \\
\text { - Compilação } \\
\text { - Led }\end{array}$ \\
\hline $2^{\circ}$ & $\begin{array}{l}\text { - Potência de } 10 \\
\text { - Código de cores resistor } \\
\text { - Associação de resistores em série e paralelo. } \\
\text { - Led RGB }\end{array}$ \\
\hline $3^{0}$ & $\begin{array}{l}\text { •Algoritmo e Sequência lógica } \\
\text { • Fluxogramas e Algoritmos }\end{array}$ \\
\hline
\end{tabular}

\begin{tabular}{|c|c|}
\hline & $\begin{array}{l}\text { - Entrada e Saída de informação } \\
\text { - Sketch } \\
\text { • Conceito de função } \\
\text { • setup(), loop(), Serial.begin() } \\
\text { - } \quad \text { Linguagem de programação } \\
\text { - Operadores matemáticos } \\
\text { - Constantes } \\
\text { - Calorimetria } \\
\text { - Termometria } \\
\text { - Sensor de temperatura }\end{array}$ \\
\hline $4^{\circ}$ & - Atividade Tinkercad \\
\hline $5^{\circ}$ & $\begin{array}{l}\text { - Linguagem de programação } \\
\text { - } \quad \text { Estrutura Básica, Sintaxe e semântica } \\
\text { - Operadores lógicos (==, !=, \& e |) } \\
\text { - Variáveis } \\
\text { - digitalWrite(),analogRead(), } \\
\text { digitalRead() } \\
\text { - Estrutura de decisão/condicionais } \\
\text {-Velocidade } \\
\text { - Movimento Uniforme e Variado } \\
\text {-2 Le Lei de Newton }\end{array}$ \\
\hline $6^{0}$ & $\begin{array}{l}\text { - Retomada experimento aula anterior. } \\
\text { - Motores elétricos } \\
\text { - Conceitos: força magnética, fluxo } \\
\text { magnético, torque } \\
\text { - Experimento construção motor controlado } \\
\text { por Arduino } \\
\text { - Botão }\end{array}$ \\
\hline $7^{0}$ & $\begin{array}{l}\text { - Estrutura de repetição } \\
\text { - Ponte H } \\
\text { - Motor } \\
\text { - Leis de Newton } \\
\text { - Gases ideais } \\
\text { - Sensor de Gás }\end{array}$ \\
\hline $8^{o}$ & $\begin{array}{l}\text { - Construção Projeto Final } \\
\text { - Display LCD } \\
\text { - Sensor de Temperatura e Umidade } \\
\text { - Temperatura máxima e mínima } \\
\text { - Umidade relativa do ar }\end{array}$ \\
\hline 9o & $\begin{array}{l}\text { - Sensor de Pressão } \\
\text { - Pressão, pressão atmosférica. } \\
\text { - Sensor de Chuva e Sensor de Umidade } \\
\text { - Sensor de luminosidade } \\
\text { - Sensor de Gás (dióxido de carbono) }\end{array}$ \\
\hline $10^{\circ}$ & $\begin{array}{l}\text { - Construção Projeto Final } \\
\text { • Apresentação dos projetos finais }\end{array}$ \\
\hline
\end{tabular}

Quadro 2 - Plano de ensino do curso 
A miniestação meteorológica era formada por: display LCD, sensor de temperatura, sensor de pressão atmosférica, sensor de chuva e sensor de umidade, sensor de luminosidade e sensor de gás. Infelizmente, devido ao tempo do curso e contratempo do excesso de feriados nos dias de sábados, em que ocorriam as aulas do curso, não houve tempo hábil para a apresentação do projeto final pelos estudantes, porém os estudantes construíram a mini estação e testaram seus sensores em todo o território do campus em que ocorria o curso, acompanhados por um professor orientador ou licenciando participante do projeto que explicavam as diferenças entre as leituras da estação. Por exemplo, a diferença da pressão atmosférica detectada pela estação no térreo do prédio em comparação com as leituras do $1^{\mathrm{o}}$ andar.

0 projeto final consolidava todo o conteúdo de computação e física para construção eletrônica (Arduino e seus componentes) e lógica (programação dos sensores). Além disso as informações exibidas pelos sensores da miniestação só fariam sentido se fossem interpretadas na perspectiva teórica da física, unindo assim, de forma indissociável, no objetivo do projeto final, as áreas de física e computação.

\section{Resultados: Os Aprendizados}

A aplicação do questionário ao final de cada aula para feedback dos estudantes foi importante para o planejamento do curso, pois um dos pontos observados na aplicação dos questionários foi a riqueza que o feedback dos estudantes traz para o fluxo contínuo de formulação e reformulação das aulas, processo necessário para qualquer prática docente. As respostas dos estudantes auxiliaram no constante processo de melhoria da prática em sala de aula ao longo de todo o curso e também no processo de construção e reconstrução do curso.

As perguntas dos questionários baseavam-se em uma atribuição de nota pelos estudantes para a aula e sugestões de melhorias. As principais sugestões de melhoria nas primeiras aulas foram: produção de material consultivo e atividades mais práticas. Durante as reuniões semanais entre professores orientadores e licenciandos, eram discutidas as sugestões e planejada uma forma de melhorar as aulas para atender às demandas dos estudantes. Como resultado, ao longo do curso, percebeu-se a satisfação dos estudantes nas demandas apresentadas. Isso também se evidencia na evolução das notas das aulas atribuídas pelos estudantes: a menor média foi 8.0, seguida de constante subida, até a média final 9.4, no último dia de aula, além do perceptível aumento de pontos positivos informados pelos estudantes nos formulários e da diminuição dos pontos negativos em comparação com as respostas em aulas anteriores.

Ao final do curso, foi aplicado questionário para os estudantes com o objetivo de obter os resultados sobre a proposta interdisciplinar do ensino de física e computação na perspectiva de experimentação, utilizando como plataforma de desenvolvimento Arduino. As perguntas, os resultados e as análises são descritos abaixo.

Podemos observar no Gráfico 1 o aumento no conhecimento autodeclarado pelos estudantes na área da física. 0 objetivo destas perguntas não era mensurar o conhecimento técnico científico dos estudantes, mas identificar a relação e o autoconhecimento do estudante com a área da física antes e depois do curso, ou seja, se o curso contribuiu em aproximar a física à realidade dos estudantes através da proposta interdisciplinar e criação ativa de experimentos ao ponto de os estudantes sentirem-se mais próximos de compreender conteúdos da física e de sentirem confiança em declarar que entendiam o que foi visto.

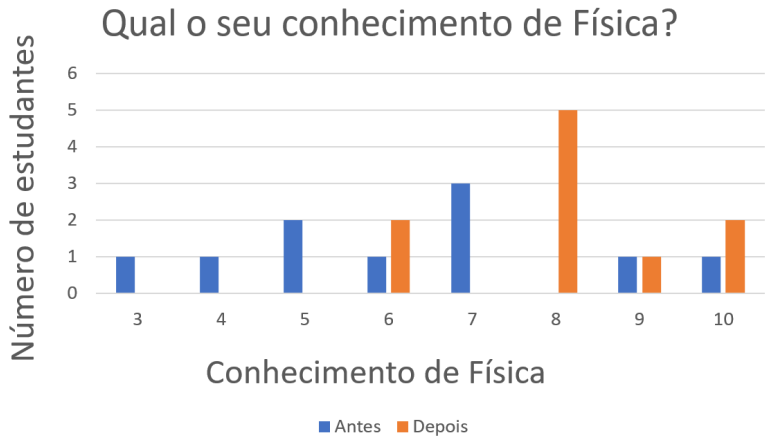

Gráfico 1 - Comparação entre o conhecimento de física antes e depois do curso.

No Gráfico 2, 80\% dos estudantes consideraram que os experimentos criados com Arduino contribuíram para o ensino dos conteúdos de física com avaliação entre 8, 9 e 10 . Já $20 \%$ dos estudantes indicaram avaliação 5, em que a contribuição foi mediana. Podemos observar que grande parte dos estudantes considera os experimentos criados com Arduino e, consequentemente, o ensino de conteúdos de computação facilitadores no entendimento dos conteúdos de física.

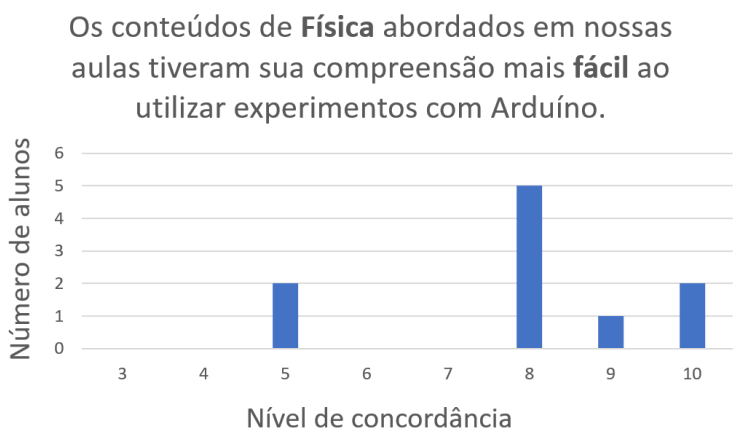

Gráfico 2 - Experimento com Arduino como facilitador na compreensão de conteúdos de física

Este ponto é reforçado nas respostas apresentadas no Gráfico 3, em que $70 \%$ dos estudantes que realizaram experimentos de física em suas escolas indicaram que os experimentos no curso com Arduino auxiliaram mais no aprendizado do conteúdo de física, sendo que $30 \%$ dos estudantes nunca realizaram experimentos de física em suas escolas. A preferência por experimentos realizados durante o curso pode ser atribuída à proposta de o estudante assumir um papel ativo na construção do experimento, não apenas de executor. Desta forma o estudante torna-se parte do processo construtivo do experimento sendo autor, produtor e executor ao aplicar os conhecimentos adquiridos de física e computação no processo construtivo e validativo do seu produto. Esta emancipação do estudante somente foi possível pela perspectiva de ensino interdisciplinar de computação e física presente no projeto do curso. 
Comparados com os experimentos realizados em sua escola e os realizados durante o curso, qual ajudou mais o seu aprendizado em FÍSICA?

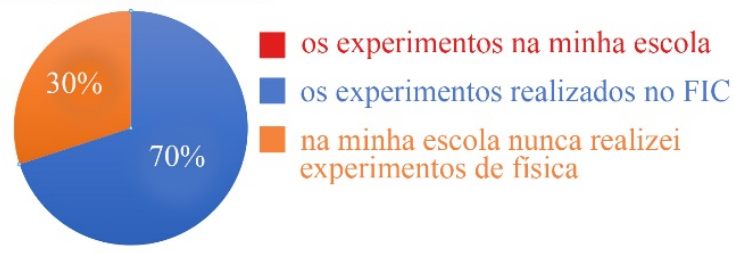

Gráfico 3 - Comparativo experimentos na escola e no curso como facilitadores no aprendizado de física

Por fim, o Gráfico 4 mostra que 100\% dos estudantes acham interessante que suas respectivas escolas adotem a abordagem/metodologia/didática utilizada nas aulas do curso FIC para o ensino de física, ou seja, o ensino de computação e física de maneira interdisciplinar por meio da criação de experimentos. Ao colocar o estudante como autor do processo experimental, não apenas como executor, podendo criar explorando sua criatividade e entendendo na prática o funcionamento do experimento embasado na teoria, aproxima-se o conhecimento da sua realidade imersa na tecnologia, ou seja, aproxima-se o conteúdo à realidade do estudante e da sociedade atual.

Na sua opinião, seria interessante sua escola utilizar a abordagem/metodologia/didática utilizada em nossas aulas para o ensino de FÍSICA em sua escola?

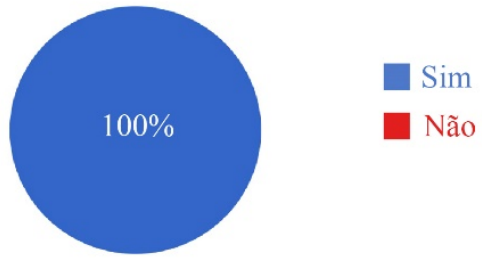

Gráfico 4 - Interesse dos estudantes na adoção da prática experimental do curso em suas escolas

Neste questionário pediu-se que os estudantes justificassem esta resposta e destacamos algumas em seguida que reforçam nossas afirmações anteriores: "teríamos mais oportunidades de conhecimento e de desenvolvimento", "A parte prática ajuda a trazer os conceitos teóricos para uma realidade mais próxima", "pois assim podermos aprender uma nova possibilidade para sistemas e descobrir algumas curiosidades de como funcionam algumas coisas". Um outro ponto interessante observado durante o curso foi a baixa taxa evasão. 0 curso iniciou-se com 12 estudantes presentes na primeira aula e na última foram 10 estudantes presentes, considerando que o curso ocorria aos sábados das $08 \mathrm{~h}$ às $11 \mathrm{~h} 40$, podemos deduzir que a temática e a metodologia empregadas conseguiram reter o interesse deste público ao longo de todo o curso.

Pela forma de avaliação utilizada no curso, entrega de projetos e observação docente, percebeu-se um forte engajamento dos estudantes nas atividades propostas a cada aula, uma vez em que todos os estudantes construíram os projetos solicitados com qualidade e autonomia. Os resultados nas avaliações condizem com a metodologia de ensino baseada na prática de projetos, resultando no êxito da aprendizagem dos estudantes referentes aos conteúdos de física e de computação de forma interdisciplinar. Por fim verificou-se que a turma, composta por estudantes da $1^{\mathrm{a}}, 2^{\underline{a}}$ e $3^{\text {a }}$ série do ensino médio, conseguiu compreender os conteúdos ainda não trabalhados em suas respectivas escolas, mostrando que a prática de projetos e o ensino de computação e física permitiram transitar verticalmente entre os conteúdos de física do ensino médio.

\section{Conclusão}

O curso "FIC Robótica e Física para estudantes do ensino médio" originou-se de uma necessidade de atualização na forma de ensinar e aprender ciências naturais em conjunto com a demanda de formação tecnológica dos estudantes desta geração. 0 ensino de conceitos de computação proporciona aos estudantes condições para serem sujeitos produtores de tecnologias e não apenas consumidores operando ferramentas, sem compreender o mundo digital ao qual estão inseridos. Em complemento, a experimentação em ciências naturais é quase uma necessidade devido às especificidades desta área, além de um facilitador de aprendizagem.

Diante desta perspectiva, foi planejado e executado o curso FIC para atender a essas necessidades, voltado para o ensino de física e computação de forma interdisciplinar. Seu objetivo foi desenvolver os letramentos científico e digitais em estudantes do ensino médio por meio de projetos para criação de experimentos, utilizando a plataforma Arduino e seus componentes.

Para a execução e planejamento contínuo do curso, na perspectiva interdisciplinar, se fez necessário montar uma equipe multidisciplinar de professores e licenciandos em física e computação que se reuniram semanalmente para o planejamento das aulas. Nestas reuniões eram analisados os dados das aulas aplicadas, levantados por meio de questionários aplicados aos estudantes e observações em sala de aula, para subsidiar a discussão do planejamento da aula seguinte de forma a atender as demandas encontradas. Esta ação foi de grande importância para a dinâmica do curso e adaptação das metodologias das aulas, buscando sempre deixar o estudante no papel ativo da aprendizagem e enfrentar os desafios pedagógicos da proposta.

Como metodologia utilizou-se a aprendizagem baseada em projetos de forma que o estudante realizava pequenos projetos ao longo da aula, abordando conteúdos de física e computação, para que ao final da aula tivesse subsídios suficientes para desenvolver, implementar e executar o experimento proposto. Ao final do curso, utilizando-se desta estratégia, atingiu-se o objetivo de desenvolver o letramento científico e digital dos estudantes considerando a produção tecnológica dos experimentos e sua realização, coletando dados e efetuando as análises necessárias. Isto se confirma nas pesquisas realizadas com os estudantes ao final do curso, em que consideraram que seu conhecimento sobre física aumentou em comparação ao início do curso, além disso grande parte consideraram os experimentos com o Arduino um facilitador de aprendizagem. Outro ponto que chama atenção é que $70 \%$ dos estudantes relataram que os experimentos realizados no curso ajudaram a compreender conceitos de física se comparados com experimentos realizados na sua escola e $30 \%$ nunca realizaram experimentos no ambiente escolar. Por fim 100\% dos estudantes acham interessante que as suas respectivas escolas adotassem a abordagem metodológica e didática para o ensino de física vivenciada dentro do curso. 
É importante também considerar a coerência entre a metodologia e o processo avaliativo, caracterizado por uma avaliação processual que envolvia feedbacks não somente dos professores para os estudantes, mas também dos estudantes para os professores.

Para o professor orientador da área da Física, o curso FIC "Robótica e Física para estudantes do ensino médio" se mostrou uma forma inovadora e eficaz para a aprendizagem dos estudantes. Este professor já havia usado recursos computacionais, como simulações computacionais, em suas aulas, mas afirmou que o uso do Arduino tornou o estudante produtor de tecnologia, trazendo engajamento, motivação, e curiosidade para os temas apresentados. A primeira mudança em relação à aula tradicional é o contato com o experimento, tornando mais próximo da realidade 0 conteúdo trabalhado. A programação trouxe também um desenvolvimento na parte lógica que é tão útil para compreender diversos assuntos da física. Por fim, a interdisciplinaridade entre computação e física permitiu ao estudante vivenciar o mundo moderno.

0 professor de Computação teve uma experiência muito positiva com este projeto, pois já teve experiência no ensino de computação para o ensino médio de uma perspectiva não interdisciplinar como ocorreu no curso. 0 ensino de computação traz benefícios na formação do jovem do século XXI, como a compreensão plena do mundo digital ao qual está imerso e aumento da capacidade de aprendizado e resolução de problemas, porém quando se alia o ensino de computação às outras áreas de ensino, quando o aprendizado extrapola 0 campo da computação entrando em outro campo, como a física, quando existe a possibilidade de autonomia para criação e resolução de problemas de outras áreas, como os experimentos criados, completa o ciclo de aprendizagem e dá sentido ao estudante. A proposta dos próprios estudantes criarem seus experimentos para aplicação e constatação do que diz a teoria completa o caminho para o aprendizado, não há mais nada escondido para o estudante assumir o papel de protagonista e produtor do seu aprendizado e dos recursos tecnológicos utilizados. Uma vez que ele é capaz de compreender a teoria física, compreender os conteúdos de computação, construir um aparato tecnológico capaz de experimentar a teoria na prática, coletar e analisar os dados obtidos na perspectiva teórica, neste momento ocorre a práxis por meio da autonomia de construção tecnológica. Desta forma a integração entre as áreas de computação e física traz oportunidades extremamente valiosas para o aprendizado.

\section{AGRADECIMENTOS}

Agradecemos todos os envolvidos que possibilitaram a implementação e execução do projeto. Ao Instituto Federal de Brasília pelo espaço fornecido, aos nossos licenciandos em física e computação pela participação no projeto e a CAPES pelos subsídios financeiros para aquisição do material do curso.

\section{REFERÊNCIAS}

[1] BORDINI et al. Computação na educação básica no Brasil: estado da arte. Porto Alegre: Rev. Inform. Teor. Apl. (Online), 2016.

[2] BRASIL. BNCC, Base Nacional Comum Curricular. Disponível em: $<$ http://basenacionalcomum.mec.gov.br/images/BNCC_EI_EF_110518_v ersaofinal_site.pdf. Acesso em: 12 maio 2020.

[3] BRUNER, J.S. Uma nova teoria da aprendizagem. Rio de Janeiro: Bloch, 1969

[4] CIEB, Centro de Inovação para a Educação Brasileira, Currículo de Referência em Tecnologia e Computação. Disponível em:
$<$ https://curriculo.cieb.net.br/assets/docs/Curriculo-de-referencia_EIe-EF_2a-edicao_web.pdf>; Acesso em 26 de janeiro 2021.

[5] MOREIRA, Marco Antônio. Teorias de aprendizagem. São Paulo: Editora pedagógica e universitária, 1999.

[6] SANTOS, C. S. Ensino de Ciências: abordagem histórico - crítica. Campinas: Armazém do ipê, 2005.

[7] SBC, Sociedade Brasileira de Computação, Diretrizes para ensino de Computação na Educação Básica. Disponível em: <https://www.sbc.org.br/documentos-da-sbc/send/203-educacaobasica/1220-bncc-em-itinerario-informativo-computacao-2>. Acesso em 12 maio 2020.

[8] SBC, Sociedade Brasileira de Computação, Itinerário Formativo da Computação. Disponível em: <https://www.sbc.org.br/documentos-dasbc/send/203-educacao-basica/1216-itinerario-formativo-dacomputacao >; Acesso em 24 de outubro 2020.

[9] VINCENT-LANCRIN, S. et al. Desenvolvimento da criatividade e do pensamento crítico dos estudantes: o que significa na escola. SP: Fundação Santillana, 2020. 